\title{
The Influence of Unilateral Subthalamic Deep Brain Stimulation on the Quality of Life of Patients with Parkinson's Disease
}

\author{
Michał SOBSTYL ${ }^{1}$, Tomasz PASTERSKI², Grażyna BRZUSZKIEWICZ-KUŹMICKA ${ }^{3}$, Marta ALEKSANDROWICZ², \\ Artur ZACZYŃSKI
}

${ }^{1}$ Neurosurgical Department of Postgraduate Medical Center, Warsaw, Poland

${ }^{2}$ Neurosurgical Department of Bródno Regional Hospital, Warsaw, Poland

${ }^{3}$ Józef Piłsudski University of Physical Education, Faculty of Rehabilitation, Warsaw, Poland

Corresponding author: Michał SOBSTYL mrsob@op.pl

\section{ABSTRACT}

AIM: To assess the health-related quality of life (HRQoL) with the Parkinson's Disease Questionnaire 39 (PDQ-39) after unilateral subthalamic deep brain stimulation (STN DBS) and to identify correlations between the changes in UPDRS (Unified Parkinson's Disease Rating Scale) scores and separate PDQ-39 QoL dimensions and PDQ summary index (SI) score at short-term follow-up (FU1) and long-term follow-up (FU2).

MATERIAL and METHODS: We evaluated 33 patients with PD after unilateral STN DBS. All patients were assessed at baseline and at FU1 and at FU2. HRQoL levels were determined by applying PDQ-39 and PD progression was evaluated by parts I-IV of the UPDRS.

RESULTS: All dimensions of PDQ-39 as well as PDQ-39 SI score were highly significantly improved at FU1. The same improvements were mostly visible at FU2 except for psychosocial functioning. The PDQ-39 SI score was reduced by $40 \%(p<0.01)$ at FU1 and by $25 \%(p<0.01)$ at FU2. A significant reduction between the UPDRS baseline scores and the UPDRS follow-up scores was noticed for medication off and on conditions under unilateral STN DBS. Interestingly, we did not find strong positive correlations between the improvements of the UPDRS scores and individual PDQ-39 dimensions as well as PDQ-39 SI score.

CONCLUSION: Improvements in PDQ-39 dimensions and PDQ-39 SI score are maintained at FU1 and except for the aspects of psychosocial functioning at FU2. Different correlations between the improvements of separate UPDRS scores on PDQ-39 dimensions require future studies in larger study groups.

KEYWORDS: Parkinson's Disease Questionnaire 39, Unilateral subthalamic deep brain stimulation, Health-related quality of life, Surgery for Parkinson's disease, Deep brain stimulation

\section{INTRODUCTION}

$\mathrm{P}$ arkinson's disease (PD) is a neurodegenerative disorder clinically diagnosed on the basis of presence of cardinal motor symptoms such as resting tremor, rigidity and bradykinesia (10). The progression of PD causes disability and functional impairment with a significantly reduced health-related quality of life ( $\mathrm{HrQoL})$. Levodopa treatment has imparted great benefits to the patients with PD by reducing motor symptoms and extending physical independence with simultaneously improved HrQoL. Bilateral subthalamic deep brain stimulation (STN DBS) is now being used as
Michał SOBSTYL

Tomasz PASTERSKI

Grażyna BRZUSZKIEWICZ-KUŹMICKA
(D) : $0000-0002-2684-3757$

(D) : 0000-0003-0619-6422

(1) : $0000-0003-3590-6470$
Marta ALEKSANDROWICZ (D) : 0000-0002-7288-3653

Artur ZACZYŃSKI 
one of the strategies to avoid the development of long-term complications associated with chronic levodopa therapy such as levodopa-induced dyskinesia (LID) or motor fluctuations. Generally, patients with advanced PD with severe LID and motor fluctuations require bilateral DBS procedures $(21,22)$. Patients with advanced PD and at an older age at surgery may not easily tolerate bilateral STN DBS procedures, unlike younger patients with moderate PD. Furthermore, a significant proportion of patients at the advanced stages of PD experiences comorbidities that may make them ineligible for STN DBS (25).

Recent studies have shown a significant interest in an earlier utilisation of STN DBS in the PD progression $(24,25)$. A recent study implementing STN DBS in the mid-stages of PD before the development of motor complications has reported not only a gain in the motor function but also an improvement in $\mathrm{HrQoL}$ using an objective disease-specific instrument such as PDQ-39 (24). DBS surgery is mainly aimed at improving HrQoL of patients, which theoretically, can be more easily achieved in younger patients with less severe PD $(24,25)$. The main advantage of an earlier STN DBS surgery may be performing a staged surgery rather than the simultaneously performed bilateral STN DBS, which is required in the advanced stages of PD $(1,14,23,29)$.

In the present case series study, we prospectively evaluated the effects of unilateral STN DBS on HrQoL validated using PDQ-39 as well as parts I-IV of UPDRS for assessment of PD features. Furthermore, we aimed to identify the correlations between the improvements in the UPDRS scores on separate dimensions of PDQ-39, and PDQ-39 summary index score (PDQ-39 SI score) at short-and long-term follow-ups.

\section{MATERIAL and METHODS}

The study comprised 33 consecutive patients (11 females and 22 males) with PD having a mild or moderate disability of LID. All the patients underwent unilateral STN DBS at the Neurosurgical Department of the Postgraduate Medical Centre from February 2012 to June 2016. The patients' characteristics and demographic data are shown in Table I.

All the patients met the clinical criteria of the United Kingdom Parkinson's Disease Society brain-bank for idiopathic PD (10). The inclusion and exclusion criteria followed CAPSITPD guidelines (5). All the patients experienced disabling asymmetric motor symptoms, such as tremors, in medicationoff condition and mild or moderate unilateral LID in medicationon condition. The inclusion criteria were as follows: idiopathic PD confirmed by a movement disorder neurologist, PD continuing for $>5$ years after the diagnosis and the presence of a disabling mild or moderate LID (rated a maximum score of 2 on item 33 of UPDRS part IV). PD was considered asymmetric when the motor scores for the more affected side of the body were at least two times higher than those for the less affected side.The cognition of the patients was assessed using the Mini-Mental State Examination (MMSE). Patients with >25 points on MMSE were considered eligible for surgery.

An L-dopa challenge was administered to confirm the drug responsiveness according to the motor part of UPDRS. The patients who qualified for the unilateral STN DBS had improvement of over $33 \%$ of PD motor symptoms when compared to medication-off condition. The medicationoff condition was defined as an overnight period free of the levodopa-containing drugs. The medication-on condition was assessed after the administration of levodopa, i.e., $50 \mathrm{mg}$ higher than the usual effective first dose taken in the morning,

Table I: The Patients' Characteristics and Demographic Data

\begin{tabular}{ll}
\hline Characteristics & Value \\
\hline Sex of operated Patients & 11 \\
Female & 22 \\
Male & $7.3 \pm 1.5$ (range: $5.4-10.2)$ \\
\hline The average disease duration till unilateral STN DBS (years) & $61.7 \pm 7.7$ (range: $41.2-72.6)$. \\
\hline The average age of the surgery (years) & $750 \pm 240$ \\
\hline Average preoperative levodopa dose (mg) & $6.6 \pm 0.9$ (range: $5-8)$ \\
\hline Short-term follow-up in months & $28.8 \pm 12.8$ (range: $12-52)$. \\
\hline Long-term follow-up in months & 22 \\
\hline Laterality of PD symptoms & 11 \\
$\quad$ Right side dominant & \\
\hline Left side dominant & 11 \\
Side of STN DBS surgery & 22 \\
$\quad$ Right STN DBS & \\
\hline
\end{tabular}

The mean time from unilateral STN DBS to the second side STN DBS surgery 8 patients (months)

$26.3 \pm 4.5$ (range: $12-44)$. 
when a patient reported the best response to the medication. As PD is a progressive neurodegenerative disorder, in some PD patients, the symptoms may not be adequately controlled by the unilateral STN DBS for longer follow-up periods. We arbitrarily marked the time of the decision for the second side surgery as the last follow-up time before undergoing the contralateral STN DBS. This situation was observed in eight patients who underwent the second side STN DBS surgery due to the progression of PD symptoms. Additional four patients were also found eligible for the second side STN DBS over the follow-up period, but because of severe comorbidities, they were refused the surgery. Three patients suffered from an ischaemic heart disease, and one patient had a small ischaemic stroke and was excluded from the second side STN DBS surgery. These comorbidities generally had no impact on the neurological status of these four patients, and the last follow-up was performed as in the remaining patients after the unilateral STN DBS. Furthermore, one patient operated on during this time period gained a great functional benefit from the unilateral STN DBS. Unfortunately, this patient developed severe cardiac insufficiency, and because of pneumonia, passed away three months after the initial STN DBS surgery.

The primary outcome measure constituted PDQ-39 dimensions as well as PDQ-39 SI score and the motor part of UPDRS (part III of UPDRS) with separate motor subscores for tremor, rigidity, bradykinesia and axial features. The answers to the PDQ-39 give the PDQ-39 SI score, as well as separate dimension scores for mobility, activities of daily living, emotional well-being, stigma, social support, cognition, communication and bodily discomfort. A summary score from 0 to 100 was calculated for all PDQ-39 dimensions. This SI is the arithmetic mean of the scores for individual domains (11). The UPDRS part III motor scores were separately assessed for tremor (items 20-21), rigidity (item 22) and bradykinesia (items 23-26,31). Axial features constituted the sum of the following items: speech (item 18), facial expression (item 19), arising from chair (item 27), posture (item 28), gait (item 29) and postural instability (item 30).

The secondary outcome measure included the assessment of mentation, behaviour and mood (part I of UPDRS), the activities of daily living (part II of UPDRS) and complications of therapy (part IV of UPDRS). LIDs were assessed in accordance with the following items: duration of dyskinesia (item 32), disability of dyskinesia (item 33), painful dyskinesia (item 34) and the presence of early morning dystonia (item 35). Fluctuations were evaluated in accordance with the following items: predictable off period (item 36), unpredictable off period (item 37), sudden off period (item 38), and duration of the off period (item 39). Preoperative and postoperative UPDRS scores were evaluated by a movement disorder neurologist. The clinical assessment also involved the Hoehn and Yahr staging scale. The individual patient's cognition was assessed using MMSE preoperatively as well as at FU1 and FU2.

The motor part of UPDRS and separate motor scores were assessed preoperatively in medication-off and medication-on conditions. The assessment routine was as follows: Firstly, the patients were assessed in medication-off condition in the morning and then in medication-on condition. In accordance with UPDRS, the same assessments took place postoperatively in medication-off condition and medicationon condition, but only when the unilateral STN DBS was switched on.

The patients were operated in medication-off condition. After the stereotactic frame fixation (Leksell G Stereotactic Frame, Elekta, Sweden) in local anaesthesia, contrast-enhanced CT scanning was performed. CT images were merged with preoperative MRI scans (T2-weighted images and T1 contrastenhanced images). The target point-subthalamic nucleuswas calculated using an indirect method in relation to the midpoint of the intercommissural line and direct methods that modified the position of the target depending on individual $\mathrm{MRI}$ scans. After the electrophysiological confirmation of the target, the DBS electrode was inserted and its position was verified with fluoroscopy. The postoperative stereotactic CT was performed to check the exact position of the implanted DBS lead and to exclude any intracranial bleeding. The patients were brought back from CT suite, and following the stereotactic frame removal, they were introduced into the general anaesthesia. A single-channel internal pulse generator was placed in the subclavicular region in the chest wall. Stimulation settings were adjusted at follow-up visits, in order to achieve the best therapeutic results.

The statistical analyses were performed using the Statistical Package for Social Sciences (SPSS version 21). The descriptive statistics (mean, standard deviation, range, confidence interval) was obtained for each variable as required. The preoperative and postoperative PDQ-39 scores and PDQ-39 SI scores as well as UPDRS scores were compared using ANOVA with Sidak post-hoc test. Spearman's rank-order correlations were used to evaluate the relationship between the study variables (UPDRS scores and PDQ-39 dimension scores). Not only a probability value of 0.05 was considered significant, but also $\mathrm{p}$-values within the range of $0.05<\mathrm{p}<0.1$ were marked.

\section{RESULTS}

The preoperative PDQ-39 and PDQ-39 SI scores were compared to the postoperative PDQ-39 scores at FU1 and FU2 using ANOVA with Sidak post-hoc test. All eight dimensions of PDQ-39 as well as PDQ-39 SI scores were highly significantly improved at FU1 $(p<0.01)$ when compared with the baseline PDQ-39 scores. On the other hand, almost the same improvements were visible at FU2, except for PDQ-39 social support, cognition and communication. These three PDQ-39 dimensions were insignificantly different when comparing the baseline scores with the postoperative scores at FU2. Eta squared as a measure of effect size showed that the means were very strongly differentiated, especially in mobility, ADL, stigma and PDQ-39 SI scores. The detailed results obtained for all dimensions of PDQ-39 as well as PDQ-39 SI score are shown in Table II.

Then, ANOVA with Sidak post-hoc test was performed to check whether there was a significant difference between the baseline motor UPDRS scores in medication-off condition 
and motor UPDRS scores at FU1 and FU2 in medicationoff stimulation-on condition. The test showed that there was a significant difference between the baseline motor UPDRS scores and individual follow-up scores for tremor, rigidity, bradykinesia and axial features. Most of the $p$-values indicated that the differences were highly significant $(p<0.01)$. For medication-off condition, the reduction of the total UPDRS motor score was $41 \%(p<0.01)$ at FU1 and $35 \%$ $(p<0.01)$ at FU2. The detailed results are shown in Table III. Secondly, ANOVA with Sidak post-hoc test was performed to check whether there was a significant difference between the baseline motor UPDRS scores in medication-on condition and motor UPDRS scores at FU1 and FU2 in medication-on stimulation-on condition. The reduction of the total UPDRS motor score in medication-on condition was $33 \%(p<0.01)$ at FU1 and 24\% $(p<0.01)$ at FU2. Additionally, the UPDRS subscores for tremor, bradykinesia and axial features were highly significantly improved $(p<0.01)$ at FU1 and FU2 when compared withthe baseline UPDRS scores in medication-on condition, except for rigidity. The detailed results are shown in Table IV.

The secondary outcome measures included the assessment of parts I, II and IV of UPDRS as well as H/Y staging system. The ANOVA with Sidak post-hoc test showed that there was a significant difference between the baseline mentation (part I of UPDRS) scores only at FU1 in medication-off and medication-on conditions, resulting in a $25 \%(p<0.01)$ and $22 \%(p<0.01)$ reduction, respectively. At FU2 in medicationoff and medication-on conditions,the mental UPDRS scores showed deterioration, when compared with the baseline mental UPDRS scores. The preoperative MMSE was 28.6 \pm 3.4 and was stable at FU1 $(28.1 \pm 3.6)$ with some not significant deterioration at FU2 $(26.2 \pm 3.2)$. The effect of unilateral STN DBS on the patients' ADL (part II of UPDRS) was significant in medication-off condition, resulting in

Table II: Patients PDQ-39 Scores Before and After Unilateral STN stimulation. Preoperative and Postoperative PDQ-39 Scores and PDQ-39 Summary Index Score were Compared by Applying ANOVA test with Sidak Post-Hoc Test. Values are Expressed as Means \pm Standard Deviations. Different Letters in Bottom Index Indicates Significant Difference Between Compared Means (Sidak Test)

\begin{tabular}{lccccc}
\hline PDQ-39 dimensions & Baseline & FU1 & FU2 & F & $\mathbf{\eta}^{2}$ \\
\hline Mobility & $37.42_{\mathrm{a}} \pm 12.86$ & $18.27_{\mathrm{b}} \pm 7.57$ & $22.96_{\mathrm{c}} \pm 6.7$ & $65.57 \ddagger$ & 0.708 \\
\hline ADL & $36.32_{\mathrm{a}} \pm 12.16$ & $18.8_{\mathrm{b}} \pm 7.95$ & $23.43_{\mathrm{c}} \pm 7.39$ & $50.53 \ddagger$ & 0.660 \\
\hline Emotional well-being & $27.93_{\mathrm{a}} \pm 10.13$ & $17.3_{\mathrm{b}} \pm 7.34$ & $20.04_{\mathrm{c}} \pm 6.04$ & $35.00 \ddagger$ & 0.564 \\
\hline Stigma & $39.23_{\mathrm{a}} \pm 10.5$ & $22.77_{\mathrm{b}} \pm 7.53$ & $27.02_{\mathrm{c}} \pm 8.25$ & $82.01 \ddagger$ & 0.752 \\
\hline Social support & $21.33_{\mathrm{a}} \pm 11.05$ & $13.97_{\mathrm{b}} \pm 10.27$ & $20.18_{\mathrm{a}} \pm 12.07$ & $7.02 \ddagger$ & 0.206 \\
\hline Cognition & $29.89_{\mathrm{a}} \pm 7.76$ & $21.21_{\mathrm{b}} \pm 8.37$ & $27.38_{\mathrm{a}} \pm 8.41$ & $17.59 \ddagger$ & 0.394 \\
\hline Communication & $33.61_{\mathrm{a}} \pm 12.87$ & $23.5_{\mathrm{b}} \pm 9.5$ & $29.09_{\mathrm{a}} \pm 13.05$ & $12.09 \ddagger$ & 0.309 \\
\hline Bodily discomfort & $36.32_{\mathrm{a}} \pm 16.38$ & $22.24_{\mathrm{b}} \pm 10.72$ & $25.66_{\mathrm{c}} \pm 11.72$ & $22.16 \ddagger$ & 0.451 \\
\hline Total & $32.75_{\mathrm{a}} \pm 7.16$ & $19.75_{\mathrm{b}} \pm 4.63$ & $24.47_{\mathrm{c}} \pm 4.86$ & $90.61 \ddagger$ & 0.770 \\
\hline
\end{tabular}

$\wedge$ - $0.05<p<0.1$; not significant (n.s.), $\dagger-p<0.05$; statistically significant,$\neq-p<0.01$ strong statistical significance, $F$ : single $F$ statistic, $\eta^{2}$ : Eta squared.

Table III: Preoperative and Postoperative UPDRS Score in off Medication Condition were Compared Using ANOVA Test with Sidak Post-Hoc Test. Values are Expressed as Means \pm Standard Deviations. Different Letters in Bottom Index Indicates Significant Difference Between Compared Means (Sidak Test)

\begin{tabular}{lccccc}
\hline UPDRS scores & Baseline & FU1 & FU2 & F & $\boldsymbol{\eta}^{2}$ \\
\hline Mentation OFF & $1.76_{\mathrm{a}} \pm 0.79$ & $1.3_{\mathrm{b}} \pm 0.64$ & $2.39_{\mathrm{a}} \pm 1.75$ & $10.27 \ddagger$ & 0.276 \\
\hline ADL OFF & $17.97_{\mathrm{a}} \pm 5.14$ & $11.33_{\mathrm{b}} \pm 3.27$ & $12.46_{\mathrm{c}} \pm 4.1$ & $104.63 \ddagger$ & 0.795 \\
\hline Axial features OFF & $8.61_{\mathrm{a}} \pm 2.28$ & $5,82_{\mathrm{b}} \pm 1.53$ & $6.82_{\mathrm{c}} \pm 1.72$ & $32.66 \ddagger$ & 0.547 \\
\hline Tremor OFF & $5.27_{\mathrm{a}} \pm 2.23$ & $1.33_{\mathrm{b}} \pm 1.05$ & $1.71_{\mathrm{b}} \pm 1.21$ & $113.61 \ddagger$ & 0.808 \\
\hline Rigidity OFF & $6.18_{\mathrm{a}} \pm 1.24$ & $3.94_{\mathrm{b}} \pm 1.12$ & $4.57_{\mathrm{c}} \pm 1.23$ & $57.41 \ddagger$ & 0.680 \\
\hline Bradykinesia OFF & $7.94_{\mathrm{a}} \pm 1.89$ & $4.85_{\mathrm{b}} \pm 1.23$ & $5.64_{\mathrm{c}} \pm 2.23$ & $39.00 \ddagger$ & 0.591 \\
\hline Total OFF & $28.03_{\mathrm{a}} \pm 3.93$ & $16.79_{\mathrm{b}} \pm 3.33$ & $18.25_{\mathrm{b}} \pm 4.4$ & $112.30 \ddagger$ & 0.806 \\
\hline
\end{tabular}

^ - 0.05<p<0.1; not significant, $\boldsymbol{\dagger}-p<0.05$; statistically significant,$\neq-p<0.01$ strong statistical significance, $\boldsymbol{F}$ : single $F$ statistic, $\boldsymbol{\eta}^{2}$ : Eta square 
$37 \%(p<0.01)$ and $30 \%(p<0.01)$ reduction at FU1 and FU2, respectively. The effect on ADL in medication-on condition was significant at FU1, resulting in $20 \%$ reduction, but this effect was lost at FU2. Unilateral STN DBS significantly reduced the complications associated with the therapy (part IVA of UPDRS). The dyskinesia score (part IVA of UPDRS) was reduced by $60 \%(p<0.01)$ at FU1 and by $58 \%(p<0.01)$ at FU2. The fluctuation score (part IVB of UPDRS) decreased by $53 \%$ $(p<0.01)$, and by $47 \%(p<0.01)$ at FU1 and FU2, respectively. The daily dose of levodopa medication decreased from the preoperative value of $880.36 \pm 352.33 \mathrm{mg}$ to $712.5 \pm 296.47$ at FU1 and increased to $854.46 \pm 230.95$ at FU2. There was a significant difference in $\mathrm{H} / \mathrm{Y}$ staging system after the surgery in medication-off stimulation-on condition when compared with the baseline $\mathrm{H} / \mathrm{Y}$ staging system in medication-off condition. The preoperative $\mathrm{H} / \mathrm{Y}$ stage in medication-off condition was $2.42 \pm 0.56$ and improved to $1.32 \pm 0.4(p<0.001)$ and $1.53 \pm$ $0.41(p<0.001)$ at FU1 and FU2, respectively. On the contrary, there was no significant difference in $\mathrm{H} / \mathrm{Y}$ staging system after the surgery in medication-on stimulation-on conditions when compared with the baseline $\mathrm{H} / \mathrm{Y}$ staging system. The preoperative $\mathrm{H} / \mathrm{Y}$ stage in medication-on condition was 1.29 \pm 0.39 and changed to $1.05 \pm 0.2(p<0.015)$ and $1.16 \pm 0.27$ $(p<0.015)$ at FU1 and FU2, respectively.

In order to examine the relationship between the improvements in the motor function and the improvements in the quality of life, Spearman's rank-order correlation coefficients were determined to compare the changes in the UPDRS scores from the baseline to FU1 and FU2 and the changes in PDQ39 scores from the baseline to FU1 and FU2. Interestingly, we did not find strong positive correlations between the improvements in the motor function at baseline to the medication-off stimulation-on condition at FU1 and FU2 visits, where the strongest effect of the unilateral STN DBS on the motor function should be anticipated. Then, the same analysis was performed for medication-on condition at baseline to medication-on stimulation-on condition, revealing no strong positive correlations between the study variables (motor part III UPDRS and dimensions of PDQ-39).

The detailed statistical analyses of all correlation coefficients using Spearman's rank-order test among UPDRS scores in medication-off and medication-on condition to individual dimensions of PDQ-39 and PDQ-39 SI scores are presented in tables, numbered from VI to IX with a description of individual correlations as negative or positive.

\section{DISCUSSION}

The present study has shown that unilateral STN DBS remains an effective and safe procedure for selected patients with moderate PD. The improvements in the motor function were paralleled by the subjective gains in HrQoL by applying PDQ39. The HrQoL levels have been investigated only in few studies after the unilateral $(2,27,28,30)$ or bilateral STN DBS $(6,7,12,16,18)$, as opposed to numerous studies focusing solely on motor UPDRS assessment $(21,22)$. It is well known that HrQoL and psychosocial functioning are much more severely compromised in patients with advanced stages of PD. Theoretically, reducing motor disabilities may be more easily achieved in less affected patients by restoring their functional independence and improving HrQoL. The HrQoL assessment is increasingly recognised as a standard instrument, which makes it possible to ascertain the true impact of DBS procedures on the patient's condition, particularly in a progressive neurodegenerative disorder such as PD.

The first study reporting the HrQoL assessment beside the UPDRS motor scores after the unilateral STN DBS was presented by Slowinski et al. (27). These authors used Parkinson's Disease Quality of Life Questionnaire (PDQL) to evaluate the effects of the unilateral STN DBS on a patient's HrQoL. In a clinical series of 24 patients, 12 patients were evaluated using PDQL questionnaire at 3 months postoperatively, revealing $15 \%$ improvement on PDQL scores in medication-on condition when compared to the baseline PDQL scores (27). This

Table IV: Preoperative and Postoperative UPDRS Score in on Medication Condition were Compared Using ANOVA Test with Sidak Post-Hoc Test. Values are Expressed as Means \pm Standard Deviations. Different Letters in Bottom Index Indicates Significant Difference Between Compared Means (Sidak Test)

\begin{tabular}{lccccc}
\hline UPDRS scores & Baseline & FU1 & FU2 & F & $\mathbf{\eta}^{2}$ \\
\hline Mentation ON & $1.24_{\mathrm{a}} \pm 0.56$ & $0.97_{\mathrm{a}} \pm 0.68$ & $1.79_{\mathrm{b}} \pm 0.88$ & $9.81 \ddagger$ & 0.267 \\
\hline ADL ON & $10.48_{\mathrm{a}} \pm 2.11$ & $8.45_{\mathrm{b}} \pm 1.99$ & $9.61_{\mathrm{a}} \pm 2.01$ & $16.03 \ddagger$ & 0.372 \\
\hline Axial features ON & $4.85_{\mathrm{a}} \pm 1.58$ & $3.12_{\mathrm{b}} \pm 1.02$ & $3.71_{\mathrm{c}} \pm 0.94$ & $24.37 \ddagger$ & 0.474 \\
\hline Tremor ON & $2.24_{\mathrm{a}} \pm 0.83$ & $0.88_{\mathrm{b}} \pm 0.86$ & $1_{\mathrm{b}} \pm 0.47$ & $66.08 \ddagger$ & 0.710 \\
\hline Rigidity ON & $3.33_{\mathrm{a}} \pm 0.99$ & $2.36_{\mathrm{b}} \pm 0.86$ & $2.89_{\mathrm{a}} \pm 1.13$ & $13.29 \ddagger$ & 0.330 \\
\hline Bradykinesia ON & $4.24_{\mathrm{a}} \pm 1.09$ & $3_{\mathrm{b}} \pm 0.87$ & $3.43_{\mathrm{b}} \pm 1.2$ & $16.19 \ddagger$ & 0.375 \\
\hline Total ON & $14.67_{\mathrm{a}} \pm 3.42$ & $9.85_{\mathrm{b}} \pm 2.17$ & $11.18_{\mathrm{c}} \pm 2.29$ & $59.37 \ddagger$ & 0.687 \\
\hline Dyskinesia ON & $2.45_{\mathrm{a}} \pm 0.79$ & $0.97_{\mathrm{b}} \pm 0.59$ & $1.04_{\mathrm{b}} \pm 0.51$ & $46.55 \ddagger$ & 0.633 \\
\hline Fluctuations ON & $2.15_{\mathrm{a}} \pm 1.03$ & $1_{\mathrm{b}} \pm 0.61$ & $1.14_{\mathrm{b}} \pm 0.45$ & $42.96 \ddagger$ & 0.614 \\
\hline
\end{tabular}

$\wedge$ - 0.05<p<0.1; not significant, $\boldsymbol{\dagger}-p<0.05$; statistically significant,$\neq-p<0.01$ strong statistical significance, F: single $F$ statistic, $\eta^{2}$ : Eta square 
relatively small QoL improvement reported in this study was attributed to the patients' older age at surgery when compared to other studies $(8,9,13,28,30)$. Another factor related to less pronounced HrQoL improvement was a unilateral STN DBS procedure, as opposed to a bilateral STN DBS procedure that generally produced a better outcome in reducing motor UPDRS scores $(9,13,21,22)$. Interestingly, these authors stated that in their experience, the motor outcome is much better improved with bilateral STN DBS, but emotional and social functioning were almost identically improved when using the unilateral STN DBS (27). Although we used another $\mathrm{HrQoL}$ scale other than those presented by Slowinski et al. (27), our results also revealed improvements in psychosocial functioning seen only at a short-term follow-up of six months postoperatively, which were lost at a long-term follow-up.

The first study quantifying the HrQoL benefit with the PDQ-39 after the unilateral STN DBS was done by Walker et al. (28). These authors followed 37 PD patients at 3, 6 and 12 months after the unilateral STN DBS. The preoperative baseline PDQ$39 \mathrm{SI}$ score was relatively high at $65.4 \pm 4.6$ among these patients; it dropped to $52.9 \pm 4.7$ at 3 months and to $47.1 \pm$ 4.1 at 6 months and increased to $54.2 \pm 4.8$ at 12 months, reflecting the reduction of PDQ-39 SI score by $20 \%, 28 \%$ and $18 \%$, respectively (28). In our series of 33 PD patients, the baseline PDQ-39 SI score was $32.75 \pm 7.16$, which dropped to $19.75 \pm 4.6$ at 6 months and $24.47 \pm 4.8$ at 28 months, reflecting the reduction ofthe postoperative PDQ-39 SI score by $40 \%$ and $25 \%$, respectively. Walker et al. concluded that unilateral STN DBS followed by a contralateral procedure later, if necessary, produced bilateral effects on PD symptoms and remained a reasonable option for patients with advanced $\mathrm{PD}$, especially with prominent symptoms asymmetry (28). The second study to date assessing HrQoL with the PDQ-39 after the unilateral DBS was presented by Zahodne et al. (30). This study directly compared the effects of the unilateral STN DBS (20 patients) and unilateral globus pallidus interna (GPi) DBS (22 patients) in 42 non-demented patients with medicationrefractory PD (30). These patients underwent excessive motor, mood, verbal fluency and PDQ-39 assessments at baseline and at 6 months following the surgery. Interestingly, despite similar motor and mood improvements, the group of GPi-stimulated patients improved more than the group of STN-stimulated patients ( $38 \%$ vs. $14.6 \%$, respectively) by comparing the PDQ-39 SI scores (30). As a group, the patients evidenced the improvements on the PDQ-39 dimensions of mobility, ADLs, emotional well-being, stigma, cognition and bodily discomfort. Patients reported overall HrQoL improvements at six months, except for PDQ-39 dimensions of social support and communication. In our patients, psychosocial functioning including the baseline subscores for social support, cognition and communication was severely disturbed when compared to the physical aspects of PDQ39 assessment. It may mean that even the patients who are not at the advanced stage of PD selected for unilateral STN DBS had severely disturbed social and family networks. Some authors have also noticed that the described family or material conflicts following DBS may prevent the improvement on social support domain $(20,30)$. Interestingly, Zahodne et al. found only the improvement on social support scores in the GPi-stimulated group 6 months postoperatively, but not in the STN-stimulated group (30). These authors highlight the presumption that unilateral STN DBS may cause more longlasting behavioural and neuropsychiatric consequences. The STN target is much smaller than the GPi target, and the STN limbic and associative subterritories are easier to be costimulated by a DBS lead reflecting presumable postsurgical mood and cognitive side effects (30).

On the contrary, we have observed a significant improvement on the social support subscore 6 months after the surgery, but this PDQ-39 dimension at 28 months after the unilateral STN DBS returned to nearly baseline scores. In our study, the same observation relates to PDQ-39 cognition and communication scores at a long-term follow-up that reached nearly the preoperative baseline scores. Zahodne et al. as well as other authors postulated that PDQ-39 communication decline may be explained by the impairment of a verbal fluency following not only bilateral but also unilateral STN DBS $(3,21,30)$. Theoretically, unilateral GPi or bilateral GPi DBS may exert better and longer-lasting improvements on psychosocial PDQ-39 dimensions (30).

The largest to-date study quantifying non-motor aspects of PD in 53 patients after the unilateral STN DBS, mainly sleep disturbances, also incorporated HrQoL assessment with the PDQ-39 (2). The preoperative baseline PDQ-39 SI score was $39.57 \pm 2.14$ and was comparable to PDQ-39 SI in our series. The PDQ-39 SI scored was reduced by $30 \%$ at 3 months $(27.80 \pm 2.01)$ and by $35 \%$ at 6 months $(26.10 \pm 1.70)$, respectively (15). At 6 months, the improvements were seen in mobility, ADLs, stigma, cognition, communication and bodily discomfort (2). The social support as in most studies was not improved, reflecting multifactorial influences like social networks, the presence of apathy and depressive symptoms that may influence especially the psychosocial dimensions of HrQoL. Table V summarizes the outcomes of the PDQ-39, UPDRS after the unilateral STN or GPi DBS in patients with PD.

Regardless of the unilateral or simultaneous bilateral STN DBS PDQ-39 social support, communication and cognition were transiently improved PDQ-39 dimensions after the DBS surgery. This can be explained by the fact that DBS may have smaller effects on non-motor symptoms such as mood, cognition, social network, sleep autonomic dysfunction, speech and swallowing. These are factors that constitute the major determinants of the quality of life that are not captured in PDQ-39. Another drawback of PDQ-39 scale is the lack of the incorporation of the side effects associated with STN DBS, such as apathy related to the reduction of daily levodopa dose, speech difficulties and impulsive behaviours as well as underreporting of axial symptoms. Apathy plays a major role in the patients' perceptions of benefit, especially in HrQoL, after a neurosurgical procedure $(19,28)$. Restoring disruption of the family life, social functioning and professional life is a challenging process influenced by multiple factors that are resistant to a DBS procedure. 
Nevertheless, the overall PDQ-39 SI score improvement in the reported studies after unilateral STN DBS varies from $14.6 \%$ to $35 \%$ at the last available follow-up that generally does not exceed 6 months and should be regarded as a short-term assessment of $\mathrm{HrQoL}(2,27,28,30)$. In the studies that report the PDQ-39 SI score improvements after the bilateral STN DBS, the improvements range from $14 \%$ to $62 \%$, which means that the bilateral STN DBS exerts more robust effects on the motor functioning and the improvement of HrQoL. In studies that report the bilateral STN DBS improvements in most PDQ39 dimensions, the improvements were still seen 2 years postoperatively $(6,7,12,16,18,26)$. In two studies reporting the long-term PDQ-39 assessments, the PDQ-39 SI scores returned to the baseline levels or remained slightly better at 5and 8-year follow-ups $(3,30)$. In the recent prospective study presented by Lezcano et al. including 69 PD patients, the PDQ-
39 SI score improved substantially by $36.5 \%$ at 1 year, but the improvement at 5 years was only $8.8 \%$ (15). In accordance with these findings, the PDQ-39 SI score at the same followup periods in $41 \mathrm{PD}$ patients in a report by Aviles-Olmos et al. improved by $24.3 \%$ and $1.8 \%$, respectively (3). AvilesOlmos et al. followed 12 patients for 8 years documenting the return of PDQ-39 SI score to the baseline level. The detailed analysis revealed that subdomains such as mobility, ADL, stigma, support and bodily discomfort showed a more sustained improvement over time. Conversely, emotional wellbeing, cognition and communication subdomains declined at 5 and 8 years (3). In the opinion of these and other authors, the development of non-levodopa-responsive PD features to bilateral STN DBS could be, at least partially, responsible for the decline in HrQoL from 5 to 8 years postoperatively.

Table V: The Outcomes of the PDQ-39 SI Score, the Motor Part III of the UPDRS as well the Complications of Levodopa Treatment Part IV of the UPDRS in Individual Studies After Unilateral STN DBS

\begin{tabular}{|c|c|c|c|c|c|c|}
\hline $\begin{array}{l}\text { uthor's } \\
\text { nd year of } \\
\text { ublication. }\end{array}$ & $\begin{array}{l}\text { UPDRS part III off } \\
\text { preoperatively/ } \\
\text { postoperatively } \\
\text { Percentage } \\
\text { improvement }\end{array}$ & $\begin{array}{l}\text { UPDRS part IV } \\
\text { preoperatively/ } \\
\text { postoperatively } \\
\text { Percentage } \\
\text { improvement }\end{array}$ & $\begin{array}{l}\text { Preoperative } \\
\text { PDQ-39 } \\
\text { SI score * } \\
\text { or PDQL ** }\end{array}$ & $\begin{array}{c}\text { Postoperative } \\
\text { PDQ-39 SI } \\
\text { score * } \\
\text { or PDQL ** }\end{array}$ & $\begin{array}{l}\text { PDQ-39 or PDQL } \\
\text { dimensions } \\
\text { improvements in } \\
\text { percentages }\end{array}$ & $\begin{array}{l}\text { Number of patients } \\
\text { at the last follow-up }\end{array}$ \\
\hline
\end{tabular}

\begin{tabular}{lcccccc}
\hline Slowinski et al. & $45.2 / 31.1$ & Part IVA 3.4/1.1 & Total PDQL & Total PDQL & Total PDQL & 12 patients assessed \\
$2007(27)$ & $31.2 \%$ & $69.2 \%$ & 102.4 & 117.2 & improved by 15\% & by PDL among 24 \\
& & & & & months
\end{tabular}

\begin{tabular}{|c|c|c|c|c|c|c|}
\hline $\begin{array}{l}\text { Zahodne et al. } \\
2009(30)\end{array}$ & $\begin{array}{c}\text { STN group } \\
43.8 / 32.2 \\
26.5 \% \\
\text { GPi group } \\
41.8 / 30.1 \\
28 \%\end{array}$ & Not reported & $\begin{array}{c}\text { STN group } \\
34.229 .2 \\
\text { GPi group } \\
36.5\end{array}$ & $\begin{array}{c}\text { STN group } \\
29.2 \\
\text { GPi group } \\
22.6\end{array}$ & $\begin{array}{c}\text { STN PDQ-39 SI } \\
\text { score improved by } \\
14 \% \\
\text { STN PDQ-39 SI } \\
\text { score improved by } \\
38 \%\end{array}$ & $\begin{array}{l}\text { STN group } 20 \\
\text { patients } \\
\text { GPi group } 22 \text { patients } \\
\text { Both groups followed } \\
\text { for } 6 \text { months }\end{array}$ \\
\hline $\begin{array}{l}\text { The present } \\
\text { study }\end{array}$ & $\begin{array}{c}28.03 / 18.25 \\
35 \%\end{array}$ & $\begin{array}{c}\text { Part IVA } 2.45 / 1.04 \\
58 \% \\
\text { Part IV B } 2.15 / 1.14 \\
47 \%\end{array}$ & 32,75 & 24,47 & $\begin{array}{c}\text { PDQ-39 SI score } \\
\text { improvement by } \\
25 \%\end{array}$ & $\begin{array}{c}33 \text { patients } \\
\text { mean } 28 \text { months }\end{array}$ \\
\hline
\end{tabular}

Abbreviations: UPDRS - Unified Parkinson's Disease Rating Scale, PDQ-39 SI score - Parkinson's Disease Questionnaire 39, PDQL Parkinson's Disease Quality of Life questionnaire, STN - subthalamic nucleus, GPi - globuspallidus pars interna. Data are presented as means without standard deviations values. PDQ-39 * - Lowe scores are indicative of better quality of life, $P D Q L$ ** - Higher scores are indicative of better quality of life. 
Table VI: Relationship Between the Improvements in UPDRS Scores in Medication-off Condition and Dimensions of PDQ-39 and PDQ$39 \mathrm{SI}$ Scores at FU1

\begin{tabular}{lccccccc}
\hline PDQ-39 dimensions & $\begin{array}{c}\text { Mentation } \\
\text { UPDRS }\end{array}$ & $\begin{array}{c}\text { ADL } \\
\text { UPDRS }\end{array}$ & $\begin{array}{c}\text { Axial features } \\
\text { UPDRS }\end{array}$ & $\begin{array}{c}\text { Tremor } \\
\text { UPDRS }\end{array}$ & $\begin{array}{c}\text { Rigidity } \\
\text { UPDRS }\end{array}$ & $\begin{array}{c}\text { Bradykinesia } \\
\text { UPDRS }\end{array}$ & $\begin{array}{c}\text { Total motor } \\
\text { UPDRS }\end{array}$ \\
\hline Mobility & 0.10 & 0.11 & 0.20 & -0.11 & -0.08 & 0.07 & -0.12 \\
\hline ADL & 0.26 & -0.09 & 0.26 & -0.15 & 0.01 & 0.00 & -0.10 \\
\hline Emotional well-being & $-0.31 \wedge$ & $0.40 \dagger$ & -0.16 & 0.23 & 0.07 & -0.08 & 0.03 \\
\hline Stigma & -0.11 & 0.08 & -0.07 & 0.10 & 0.13 & 0.21 & 0.17 \\
\hline Social support & -0.22 & 0.24 & 0.06 & -0.09 & 0.05 & 0.17 & 0.08 \\
\hline Cognition & -0.15 & 0.11 & 0.26 & 0.04 & 0.21 & 0.19 & $0.32 \dagger$ \\
\hline Communication & 0.11 & 0.06 & 0.28 & -0.10 & 0.15 & 0.20 & 0.02 \\
\hline Bodily discomfort & -0.06 & 0.06 & -0.11 & 0.17 & -0.19 & -0.12 & -0.23 \\
\hline Total & 0.10 & 0.11 & 0.20 & -0.11 & -0.08 & 0.07 & -0.12 \\
\hline
\end{tabular}

$\wedge$ - $0.05<p<0.1$; a favourable statistical trend, $\boldsymbol{t}-p<0.05$; statistically significant $\neq-p<0.01$ strong statistical significance.

Table VII: Relationship Between the Improvements in Updrs Scores in Medication-off Condition and Dimensions of PDQ-39 and PDQ39 SI Scores at FU2

\begin{tabular}{lccccccc}
\hline PDQ-39 dimensions & $\begin{array}{c}\text { Mentation } \\
\text { UPDRS }\end{array}$ & $\begin{array}{c}\text { ADL } \\
\text { UPDRS }\end{array}$ & $\begin{array}{c}\text { Axial features } \\
\text { UPDRS }\end{array}$ & $\begin{array}{c}\text { Tremor } \\
\text { UPDRS }\end{array}$ & $\begin{array}{c}\text { Rigidity } \\
\text { UPDRS }\end{array}$ & $\begin{array}{c}\text { Bradykinesia } \\
\text { UPDRS }\end{array}$ & $\begin{array}{c}\text { Total motor } \\
\text { UPDRS }\end{array}$ \\
\hline Mobility & -0.23 & 0.13 & 0.08 & -0.05 & 0.21 & 0.11 & 0.18 \\
\hline ADL & -0.07 & 0.14 & 0.04 & -0.04 & 0.10 & -0.14 & -0.07 \\
\hline Emotional well-being & -0.10 & 0.09 & $-0.41 \dagger$ & 0.01 & 0.02 & 0.02 & 0.20 \\
\hline Stigma & -0.21 & 0.23 & 0.04 & 0.26 & -0.09 & -0.22 & -0.23 \\
\hline Social support & $-0.38 \dagger$ & 0.10 & 0.29 & $-0.48 \dagger$ & -0.07 & 0.20 & $-0.38 \dagger$ \\
\hline Cognition & -0.17 & 0.26 & $0.37 \wedge$ & 0.17 & -0.15 & -0.14 & 0.06 \\
\hline Communication & -0.09 & 0.27 & 0.15 & -0.20 & -0.10 & -0.19 & 0.10 \\
\hline Bodily discomfort & -0.03 & 0.10 & -0.01 & 0.19 & -0.01 & -0.04 & 0.05 \\
\hline Total & -0.29 & 0.30 & 0.15 & -0.07 & -0.01 & -0.06 & -0.03 \\
\hline
\end{tabular}

^ - 0.05<p<0.1; a favourable statistical trend, $\dagger-p<0.05$; statistically significant $¥-p<0.01$ strong statistical significance.

Table VIII: Relationship Between the Improvements in UPDRS Medication-On Condition and PDQ-39 Quality-of-Life Score at FU1

\begin{tabular}{lccccccccc}
\hline $\begin{array}{l}\text { PDQ-39 } \\
\text { dimensions }\end{array}$ & $\begin{array}{c}\text { Mentation } \\
\text { UPDRS }\end{array}$ & $\begin{array}{c}\text { ADL } \\
\text { UPDRS }\end{array}$ & $\begin{array}{c}\text { Axial } \\
\text { features } \\
\text { UPDRS }\end{array}$ & $\begin{array}{c}\text { Tremor } \\
\text { UPDRS }\end{array}$ & $\begin{array}{c}\text { Rigidity } \\
\text { UPDRS }\end{array}$ & $\begin{array}{c}\text { Bradykinesia } \\
\text { UPDRS }\end{array}$ & $\begin{array}{c}\text { Total } \\
\text { motor } \\
\text { UPDRS }\end{array}$ & Dyskinesia Fluctuations \\
\hline Mobility & 0.10 & 0.07 & 0.19 & -0.15 & 0.01 & -0.17 & -0.01 & 0.19 & 0.06 \\
\hline ADL & 0.06 & -0.09 & 0.09 & $-0.36 \dagger$ & -0.11 & 0.00 & 0.00 & -0.07 & 0.29 \\
\hline Emotional well-being & -0.18 & -0.02 & 0.02 & 0.12 & -0.05 & -0.14 & 0.02 & 0.09 & 0.21 \\
\hline Stigma & $0.30^{\wedge}$ & -0.05 & -0.13 & -0.15 & -0.11 & 0.14 & -0.11 & $-0.35 \dagger$ & -0.17 \\
\hline Social support & 0.02 & -0.21 & 0.07 & -0.04 & -0.05 & -0.13 & 0.00 & -0.13 & $0.42 \dagger$ \\
\hline Cognition & -0.14 & 0.06 & 0.01 & -0.06 & $0.33^{\wedge}$ & 0.04 & 0.19 & -0.18 & 0.20 \\
\hline Communication & 0.01 & 0.10 & $0.34^{\wedge}$ & -0.14 & 0.23 & 0.13 & 0.26 & 0.29 & $0.32^{\wedge}$ \\
\hline Bodily discomfort & 0.04 & -0.19 & -0.06 & 0.20 & -0.29 & -0.22 & -0.22 & 0.07 & 0.07 \\
\hline Total & 0.10 & 0.07 & 0.19 & -0.15 & 0.01 & -0.17 & -0.01 & 0.19 & 0.06 \\
\hline
\end{tabular}

$\wedge$ - $0.05<p<0.1$; a favourable statistical trend, $\dagger-p<0.05$; statistically significant $¥-p<0.01$ strong statistical significance. 
Sobstyl M. et al: Unilateral Subthalamic Deep Brain Stimulation

Table IX: Relationship Between the Improvements in UPDRS Medication-on Condition and PDQ-39 Quality-of-Life Scores at FU2

\begin{tabular}{lccccccccc}
\hline $\begin{array}{l}\text { PDQ-39 } \\
\text { dimensions }\end{array}$ & $\begin{array}{c}\text { Mentation } \\
\text { UPDRS }\end{array}$ & $\begin{array}{c}\text { ADL } \\
\text { UPDRS }\end{array}$ & $\begin{array}{c}\text { Axial } \\
\text { features } \\
\text { UPDRS }\end{array}$ & $\begin{array}{c}\text { Tremor } \\
\text { UPDRS }\end{array}$ & $\begin{array}{c}\text { Rigidity } \\
\text { UPDRS }\end{array}$ & $\begin{array}{c}\text { Bradykinesia } \\
\text { UPDRS }\end{array}$ & $\begin{array}{c}\text { Total } \\
\text { motor } \\
\text { UPDRS }\end{array}$ & Dyskinesia Fluctuations \\
\hline Mobility & 0.15 & 0.03 & 0.10 & 0.24 & 0.12 & -0.30 & -0.06 & 0.11 & 0.26 \\
\hline ADL & 0.11 & 0.08 & 0.12 & 0.12 & 0.13 & -0.27 & -0.02 & -0.27 & 0.08 \\
\hline Emotional well-being & 0.14 & -0.14 & -0.11 & 0.19 & $-0.45 \dagger$ & -0.16 & $-0.33^{\wedge}$ & -0.14 & $0.43 \dagger$ \\
\hline Stigma & 0.16 & $0.34 \wedge$ & 0.24 & 0.11 & 0.21 & -0.01 & 0.25 & $-0.39 \dagger$ & 0.06 \\
\hline Social support & $-0.38 \dagger$ & -0.19 & 0.14 & $-0.35 \wedge$ & 0.07 & -0.08 & -0.02 & -0.08 & 0.06 \\
\hline Cognition & -0.21 & $0.47 \dagger$ & $0.37 \wedge$ & 0.01 & 0.29 & -0.17 & 0.25 & -0.15 & $0.36^{\wedge}$ \\
\hline Communication & -0.27 & 0.21 & 0.09 & 0.13 & 0.04 & 0.22 & 0.27 & 0.17 & 0.23 \\
\hline Bodily discomfort & 0.18 & 0.13 & 0.21 & 0.19 & 0.12 & -0.18 & 0.08 & -0.02 & $0.35^{\wedge}$ \\
\hline Total & -0.05 & 0.19 & 0.27 & 0.13 & 0.14 & -0.20 & 0.11 & -0.13 & $0.41 \dagger$ \\
\hline
\end{tabular}

$\wedge$ - 0.05<p<0.1; a favourable statistical trend, $\boldsymbol{\dagger}-p<0.05$; statistically significant $¥-p<0.01$ strong statistical significance.

The magnitude of the improvement of UPDRS scores after the unilateral versus bilateral procedures in relation to HrQoL may have a relevant impact on finding positive correlations reflected in PDQ-39. This may partially explain the findings in our study. Surprisingly, we have not found strong positive correlations between ADL UPDRS scores and several psychosocial domains of PDQ-39, including emotional well-being, social support, cognition and bodily discomfort, as well as PDQ-39 SI scores. In contrast to other investigators, we have not found positive correlations between the improvements in the total motor UPDRS scores or separate UPDRS motorsubscores on individual PDQ-39 dimensions or even PDQ-39 SI score $(3,15,18)$. Furthermore, we have found only weak or moderate positive correlations between the study variables, but none of these correlations was on a strong level. This may be partially explained by the fact that finding strong correlations may require studying larger patient groups. Another factor, as stated above, is related to a smaller magnitude of the improvement after a unilateral DBS procedure versus bilateral DBS procedures.

Generally, the unilateral DBS procedures have a smaller impact on HrQoL obscuring finding strong correlations between the study variables such as UPDRS scores and PDQ39 dimensions. In line with this view, the studies reporting the outcomes of bilateral STN DBS have found strong positive correlations between the study variables such as the UPDRS motor scores and the PDQ-39 dimensions $(4,6,12,16)$. For instance, in a study conducted by Lyons and Pahwa who reported the outcomes of 43 PD patients at a long-term follow-up (more than 24 months), the strongest correlation between the improvements in the PDQ-39 SI score and motor UPDRS score was an improvement in bradykinesia, indicating that bradykinesia was the motor symptom that exerted the strongest impact on HrQoL (18). In the recent prospective study presented by Lezcano et al. including 69 patients, the main predictor for the improvement of PDQ-39 SI score 5 years after the bilateral STN DBS was the improvement of UPDRS motor scores, mainly rigidity, bradykinesia and axial scores, except tremor (15). These findings suggest that hypokinetic features may have a stronger impact on HrQoL than tremor at a long-term follow-up after the bilateral STN DBS $(15,18)$.

The possible reasons for not finding positive correlations at a strong level in our study were multifactorial and included a small study group, unilateral versus bilateral STN DBS procedures, lower UPDRS baseline scores and lower PDQ39 dimensions and PDQ-39 SI baseline scores. These factors may also explain why some separate motor UPDRS changes have non-significant correlations with PDQ-39 dimensions of HrQoL improvements in our study or these correlations remained at weak or moderate levels. Another limitation is the lack of a control group to compare the individuals who had unilateral STN DBS with a non-surgery group. To our knowledge, only one study presented by Just and Ostergaard compares a surgery group with a similar group of patients who did not undergo surgery and were recruited from a waiting list for bilateral STN DBS (21). Another approach to investigate the effects of the surgery on HrQoL in PD patients would be the comparison of unilateral (staged, if required) and bilateral STN DBS procedures. In our opinion, this issue is of interest because it would enable studying the effects on HrQoL of not only the unilateral STN DBS, but it will look at the point if the second side STN DBS would improve the patient's functioning.

Another limitation in our study is the lack of assessing apathy and depressive symptoms, which can profoundly affect the patient's subjective HrQoL status after the surgery. Furthermore, the patients implanted with STN DBS, followed for longer periods exceeding 5 or even 10 years, may face, as stated above, several limitations of HrQoL resulting from STN stimulation-induced neuropsychiatric symptoms and long levodopa intake and from the appearance of stimulation-resistant PD features. These observations resulted in the development of a new deep brain stimulation impairment scale (DBS-IS). This 
new scale plays a special attention to the problems seen in the DBS patient population such as postural instability, gait and speaking problems, cognitive impairment, impulsivity and DBS hardware-related complications. This DBS-IS is not designed to replace the PDQ-39. It is complementary to PDQ39 and can assist in DBS candidate selection. Further studies, preferentially with larger study populations, followed up for longer periods after the unilateral STN DBS are warranted to determine the impact of the unilateral DBS on the patients' subjective HrQoL. Another field of investigation would be the assessment of the unilateral DBS versus the bilateral DBS in the STN or GPi as well as the study of HrQoL in the staged STN or GPi DBS procedures.

\section{CONCLUSIONS}

1. Our findings indicate that unilateral STN DBS significantly improved HrQoL dimensions of mobility, ADL, emotional well-being, stigma and bodily discomfort as well as PDQ$39 \mathrm{SI}$ scores at FU1 and FU2.

2. Psychosocial aspects such as social support, cognition and communication in contrast to physical aspects of $\mathrm{HrQoL}$ remain deteriorated at FU2.

3. Unilateral STN DBS has significantly reduced motor symptoms of PD at FU1 and FU2 in medication-off condition as well as levodopa-induced complications in medication-on condition.

4. We have not found positive correlations between the improvements seen in motor scores of UPDRS and separate PDQ-39 dimensions and PDQ-39 SI score. Most correlations seen in our study were on weak or moderate level as opposed to the studies reporting the effects of bilateral STN DBS.

\section{REFERENCES}

1. Alberts JL, Hass CJ, Vitek JL, Okun MS: Are two leads always better than one: An emerging case for unilateral subthalamic deep brain stimulation in Parkinson's disease. Exp Neurol 214(1):1-5, 2008

2. Amara AW, Standaert DG, Guthrie S, Cutter G, Watts $\mathrm{RL}$, Walker HC: Unilateral subthalamic nucleus deep brain stimulation improves sleep quality in Parkinson's disease. Parkinsonism Relat Disord 18(1):63-68, 2012

3. Aviles-Olmos I, Kefalopoulou Z, Tripoliti E, Candelario J, Akram H, Martinez-Torres I, Jahanshahi M, Foltynie T, Hariz $\mathrm{M}$, Zrinzo L, Limousin P: Long-term outcome of subthalamic nucleus deep brain stimulation for Parkinson's disease using an MRI-guided and MRI-verified approach. J Neurol Neurosurg Psychiatry 85(12):1419-1425, 2014

4. Daniels C, Krack P, Volkmann J, Raethjen J, Pinsker MO, Kloss M, Tronnier V, Schnitzler A, Wojtecki L, Bötzel K, Danek A, Hilker R, Sturm V, Kupsch A, Karner E, Deuschl G, Witt K: Is improvement in the quality of life after subthalamic nucleus stimulation in Parkinson's disease predictable? Mov Disord 26(14):2516-2521, 2011
5. Defer GL, Widner H, Marié RM, Rémy P, Levivier M: Core assessment program for surgical interventional therapies in Parkinson's disease (CAPSIT-PD). Mov Disord 14(4):572-584, 1999

6. Drapier S, Raoul S, Drapier D, Leray E, Lallement F, Rivier I: Only physical aspects of quality of life are significantly improved by bilateral subthalamic stimulation in Parkinson's disease. J Neurol 252(5):583-588, 2005

7. Erola T, Karinen P, Heikkinen E, Tuominen J, Haapaniemi T, Koivukangas J, Myllylä V: Bilateral subthalamic nucleus stimulation improves health-related quality of life in Parkinsonian patients. Parkinsonism Relat Disord 11(2):89-94, 2005

8. Germano IM, Gracies JM, Weisz DJ, Tse W, Koller WC, Olanow CW: Unilateral stimulation of the subthalamic nucleus in Parkinson disease: A double-blind 12-month evaluation study. J Neurosurg 101(1):36-42, 2004

9. Hamani C, Richter E, Schwalb JM, Lozano AM: Bilateral subthalamic nucleus stimulation for parkinson's disease: A systematic review of the clinical literature. Neurosurgery 56(6):1313-1324, 2005

10. Hughes AJ, Daniel SE, Kilford L, Lees AJ: Accuracy of clinical diagnosis of idiopathic Parkinson's disease. A clinico-pathological study of 100 cases. J Neurol Neurosurg Psychiatry 55(3):181-184 1992

11. Jenkinson C, Fitzpatrick R, Peto V, Greenhall R, Hyman N: The Parkinson's Disease Questionnaire (PDQ-39): Development and validation of a Parkinson's disease summary index score. Age Ageing 26(5):353-357, 1997

12. Just $\mathrm{H}$, Ostergaard $\mathrm{K}$ : Health-related quality of life in patients with advanced Parkinson's disease treated by deep brain stimulation of the subthalamic nuclei. Mov Disord 17(3):539545, 2002

13. Kim HJ, Paek SH, Kim JY, Lee JY, Lim YH, Kim DG, Jeon BS: Two-year follow-up on the effect of unilateral subthalamic deep brain stimulation in highly asymmetric Parkinson's disease. Mov Disord 24(3):329-335, 2009

14. Kumar R, Lozano AM, Sime E, Halket E, Lang AE: Comparative effects of unilateral and bilateral subthalamic nucleus deep brain stimulation. Neurology 53 (3):561-566, 1999

15. Lezcano E, Gómez-Esteban JC, Tijero B, Bilbao G, Lambarri I, Rodriguez O, Villoria R, Dolado A, Berganzo K, Molano A, de Gopegui ER, Pomposo I, Gabilondo I, Zarranz JJ: Long-term impact on quality of life of subthalamic nucleus stimulation in Parkinson's disease. J Neurol 263(5):895-905, 2016

16. Lezcano E, Gómez-Esteban JC, Zarranz JJ, Lambarri I, Madoz P, Bilbao G, Pomposo I, Garibi J: Improvement in quality of life in patients with advanced Parkinson's disease following bilateral deep-brain stimulation in subthalamic nucleus. Eur $\mathrm{J}$ Neurol 11(7):451-454, 2004

17. Linazasoro G, Van Blercom N, Lasa A: Unilateral subthalamic deep brain stimulation in advanced Parkinson's disease. Mov Disord 18(6):713-716, 2003

18. Lyons KE, Pahwa R: Long-term benefits in quality of life provided by bilateral subthalamic stimulation in patients with Parkinson disease. J Neurosurg 103(2):252-255, 2005 
19. Martinez-Fernandez R, Pelissier P, Quesada JL, Klinger $H$, Lhommée E, Schmitt E, Fraix V, Chabardes S, Mertens P, Castrioto A, Kistner A, Broussolle E, Pollak P, Thobois S, Krack $P$ : Postoperative apathy can neutralise benefits in quality of life after subthalamic stimulation for Parkinson's disease. J Neurol Neurosurg Psychiatry 87(3):311-318, 2016

20. Martínez-Martín P, Deuschl G: Effect of medical and surgical interventions on health-related quality of life in Parkinson's. Mov Disord 6:757-765, 2007

21. Ostergaard K, Sunde N, Dupont E: Effects of bilateral stimulation of the subthalamic nucleus in patients with severe Parkinson's disease and motor fluctuations. Mov Disord 17(4): 693-700, 2002

22. Romito LM, Scerrati M, Contarino MF, Bentivoglio AR, Tonali P, Albanese A: Long term follow-up of subthalamic nucleus stimulation in Parkinson's disease. Neurology 58(10):15461550, 2002

23. Samii A, Kelly VE, Slimp JC, Shumway-Cook A, Goodkin $\mathrm{R}$ : Staged unilateral versus bilateral subthalamic nucleus stimulator implantation in Parkinson disease. Mov Disord 22(10):1476-1481, 2007

24. Schuepbach WM, Rau J, Knudsen K, Volkmann J, Krack P, Timmermann L, Hälbig TD, Hesekamp H, Navarro SM, Meier $\mathrm{N}$, Falk $\mathrm{D}$, Mehdorn $\mathrm{M}$, Paschen $\mathrm{S}$, Maarouf $\mathrm{M}$, Barbe MT, Fink GR, Kupsch A, Gruber D, Schneider GH, Seigneuret E, Kistner A, Chaynes P, Ory-Magne F, Brefel Courbon C, Vesper J, Schnitzler A, Wojtecki L, Houeto JL, Bataille B, Maltête D, Damier P, Raoul S, Sixel-Doering F, Hellwig $D$, Gharabaghi A, Krüger R, Pinsker MO, Amtage F, Régis JM, Witjas T, Thobois S, Mertens P, Kloss M, Hartmann A, Oertel WH, Post B, Speelman H, Agid Y, Schade-Brittinger C, Deuschl G; EARLYSTIM Study Group: Neurostimulation for Parkinson's disease with early motor complications. N Engl J Med 368(7):610-622, 2013
25. Schüpbach WM, Maltête D, Houeto JL, du Montcel ST, Mallet L, Welter ML, Gargiulo M, Béhar C, Bonnet AM, Czernecki V, Pidoux B, Navarro S, Dormont D, Cornu P, Agid Y: Neurosurgery at an earlier stage of Parkinson disease: $A$ randomized, controlled trial. Neurology 68(4):267-271, 2007

26. Siderowf A, Jaggi JL, Xie SX, Loveland-Jones C, Leng L, Hurtig H, Colcher A, Stern M, Chou KL, Liang G, Maccarone $H$, Simuni T, Baltuch G: Long-term effects of bilateral subthalamic nucleus stimulation on health-related quality of life in advanced Parkinson's disease. Mov Disord 21(6):746753, 2006

27. Slowinski JL, Putzke JD, Uitti RJ, Lucas JA, Turk MF, Kall BA, Wharen RE: Unilateral deep brain stimulation of the subthalamic nucleus for Parkinson disease. J Neurosurg 106(4):626-632, 2007

28. Walker HC, Watts RL, Guthrie S, Wang D, Guthrie BL: Bilateral effects of unilateral subthalamic deep brain stimulation on Parkinson's disease at 1 year. Neurosurgery 65(2):302-309, 2009

29. Verhagen L, Arzbaecher J, Sierens D, Myre B, Verwey NA, Leurgans S, Bakay Roy A: Unilateral deep brain stimulation of the subthalamic nucleus: A valuable alternative? Neurology 60 (5 Supplement 1): A119, Ch 11, 2003

30. Zahodne LB, Okun MS, Foote KD, Fernandez HH, Rodriguez RL, Wu SS, Kirsch-Darrow L, Jacobson CE 4th, Rosado C, Bowers D: Greater improvement in quality of life following unilateral deep brain stimulation surgery in the globus pallidus as compared to the subthalamic nucleus. J Neurol 256(8):1321-1329, 2009 